\title{
FENOMENOLOGÍA DE LA CONFLICTIVIDAD
}

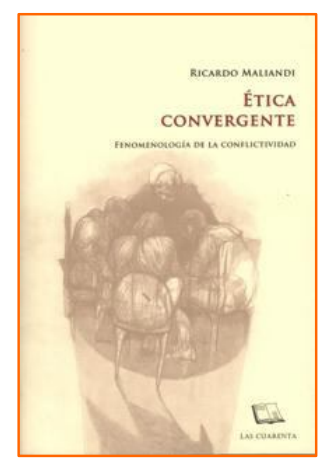

MALIANDI, RICARDO. Ética Convergente. Tomo I. "Fenomenología de la conflictividad". Buenos Aires, Ediciones Las Cuarenta, 2010. ISBN 978-987-1501-13-7.

Andrés Crelier (UNMDP-CONICET)

La Ética Convergente, de Ricardo Maliandi, es el fruto de una vida de trabajo filosófico. Le he oído reiteradamente decir al propio Ricardo Maliandi que nunca iba a ver publicada esta obra y siempre me pareció en cierto modo obvia esta afirmación, no por la edad de Maliandi sino el índice propuesto parecía humanamente irrealizable para cualquier persona. Pero, para mi sorpresa y la de quienes lo conocemos, ahora se muestra no sólo que el Maliandi pragmático le ganó al investigador encerrado en su oficina de trabajo, sino también que la obra ya estaba en gran medida escrita, pudiendo salir finalmente a la luz, al menos en una primera parte.

Ciertamente, el texto que tenemos ante nosotros no propone tesis que no hayamos leído en artículos, en compilaciones de textos o escuchado defender a Maliandi en conferencias o discusiones. Pero en todas las otras ocasiones eran desprendimientos de esta obra en ejecución, y ahora es la obra misma, la matriz original, la que tenemos impresa ante nosotros. Como una primera ventaja, entonces, para citar, criticar o los temas propios de la filosofía de Maliandi, no hay ya que indagar en sus compilaciones o infinidad de artículos y conferencias, basta ahora con remitirse a la Ética convergente misma.

Esta propuesta no se restringe al terreno de la ética, puesto que contiene una diversidad de concepciones antropológicas, metafísicas, políticas, entre 
otras. Y las contiene no al modo de un mosaico sincrético sino ordenadas arquitectónicamente según un esquema general, extraído de la noción de conflictividad a priori, que adopta diferentes formas (las dimensiones de la razón o estructura del ethos, por ejemplo). Pero el "sistema" es lo suficientemente flexible como para incorporar piezas nuevas y dar lugar a nuevos ejes de investigación.

Por eso se puede afirmar, como el propio Maliandi reconoce, que la propuesta consiste en un verdadero programa de trabajo. Por lo pronto, este programa integra dentro de sí, en lo que ya ha sido escrito, a los pensadores que han sido su fuente y a las críticas recibidas, presentando como resultado un conjunto de herramientas conceptuales que constituyen un aporte novedoso, tanto local como para la filosofía universal. Así, es posible trabajar "dentro" de la ética convergente entendida como una orientación conceptual paradigmática, un modelo y método de trabajo. Maliandi no sólo escribe un libro que expone una concepción filosófica y argumenta en una serie de sentidos sino que escribe un marco para su propia investigación y la de otros.

La publicación de la Ética Convergente se organiza, como indica el autor en el prólogo, en tres tomos que responden a una división metodológica que tiene su origen en Hartmann: fenomenología, aporía y teoría. El que acaba de ver la luz, cuyo subtítulo reza "Fenomenología de la conflictividad", describe las características de lo conflictivo, en general primero y en el ámbito de la ética después. El segundo tomo se dedicará a los principales problemas éticos que se derivan de la conflictividad: la fundamentación y los antagonismos entre principios. El tercer tomo, finalmente, contendrá la propuesta teórica de la Ética Convergente misma, incluyendo cuestiones de aplicación.

Si bien el trabajo fenomenológico está reservado preferentemente a este primer tomo, la propuesta de una "fenomenología de la conflictividad", en el subtítulo de este primer tomo, responde adecuadamente, a mi modo de ver, al estilo de trabajo filosófico de Maliandi. A tono con la fenomenología, se trata de mostrar en este caso que las modalidades de conflictos conforman estructuras complejas y a priori, y de analizar una diversidad de estas modalidades y estructuras que son condiciones de posibilidad de los conflictos empíricos.

Así, el estilo de Maliandi no consiste en primer término en una argumentación de determinadas tesis frente a otras corrientes o posiciones 
filosóficas sino en mostrar estas estructuras, interviniendo en diversas discusiones en el marco de esta tarea fenomenológica. Este "estilo arquitectónico" de trabajo tiene la virtud de que se aviene con la idea de programa de trabajo que sugiere incluso direcciones todavía no desarrolladas.

En una división y presentación general de su contenido, el primer tomo incluye un análisis fenomenológico del concepto de conflictividad y una aproximación detallada a la conflictividad en el ámbito de la ética. El "hilo de Ariadna" para orientarnos es el concepto de conflictividad, el cual permite ingresar, permanecer y orientarse en el mundo de la Ética Convergente, que es una "Ética de la Conflictividad".

Lo primero que salta a la vista es que Maliandi no concibe a la ética como una disciplina aislada (aunque sí por cierto autónoma). Ante todo, en este tomo la Ética Convergente está ligada especialmente con ciertas consideraciones metafísicas, que conforman lo que Maliandi ha denominado una metafísica provisional de la conflictividad. Creo que puede afirmarse que la metafísica ronda las diversas tematizaciones aquí presentadas en una propuesta en principio fenomenológica. Esto se advierte en la toma de posición respecto de posiciones tradicionales respecto de la conflictividad (el fondo de la realidad es conflictivo o es armónico, por ejemplo), en la idea de que la conflictividad, al igual que la libertad, es un supuesto para la ética y en diversas tematizaciones que toman como objeto estructuras de la realidad, especialmente humana (sociales y políticas).

Como insiste Maliandi, no se trata de fundamentar la ética en la metafísica, sino de de señalar que la fundamentación ética debe tener en cuenta la conflictividad, el carácter inevitablemente conflictivo en principio de la moralidad. Así, puede afirmarse que la puerta de entrada que la Ética Convergente propone a los problemas éticos es una descripción de la estructura conflictiva de la realidad. El punto de partida no es un énfasis en que estamos ya en condiciones de proponer una filosofía - especialmente una ética- "posmetafísica", sino en que tenemos que tener alguna noción previa de la conflictividad para que tenga sentido proponer una ética. Concretamente, si buscamos denodadamente un procedimiento efectivo y legítimo para solucionar los conflictos prácticos, es porque asumimos que la vida humana está inmersa en ellos, al menos frecuentemente. 
Sin aventurarse entonces en especulaciones ontológicas, algo que luego del giro lingüístico resulta cuanto menos sospechoso, Maliandi cree en suma sensato postular la existencia de "estructuras conflictivas" en la realidad. Esta tematización es tanto fenomenológica -ya que devela estructuras o sistemas a priori sin prejuzgar su naturaleza- como metafísica, en tanto reconoce que estas estructuras o sistemas involucran a las cosas del mundo. La relación con la ética consiste en que si no hubiera conflictos, el ethos sería superfluo; si sólo hubiera conflictos, el ethos sería imposible. Cada fenómeno ético es testimonio de la conflictividad constitutiva de la realidad. Como señalé, Maliandi denomina "provisional" a esta metafísica, y en ocasiones yo la he llamado "mínima", pues en cierto modo una metafísica no puede ser "provisional", y de hecho los elementos básicos que Maliandi adopta para describir la realidad no parecen, en principio, sustituibles. Se trata en todo caso de la asunción de elementos continuamente presentes en el pensamiento occidental desde sus inicios.

En esta tarea fenomenológico-conceptual Maliandi diferencia el concepto de conflictividad de otros conceptos por cierto emparentados, pero que no resultan del todo equivalentes, como el de complejidad o el de polaridad. Los tipos de conflicto, los modos en los que se puede hablar de conflicto, son expuestos con todo detalle, señalando esquemas posibles de enfrentamiento, desgarro, colisiones, etc. Se muestra que la conflictividad como tal puede abordarse sin necesidad de tener en cuenta necesariamente un campo empírico determinado, aunque las ilustraciones vienen de la propia experiencia.

Maliandi propone asimismo una explicación de la metodología del estudio de la conflictividad, incluyendo los niveles de reflexión que permiten diversas aproximaciones al fenómeno del ethos. Piensa que la conflictividad misma puede utilizarse como metodología para acercarse a dicho fenómeno. Para esto expone las estructuras conflictivas básicas: la sincrónica, que opone lo universal a lo particular, y la diacrónica, que opone la permanencia al cambio. Estas estructuras básicas deben entenderse, señala el autor, en el marco de sistemas dinámicos.

Me parece relevante acotar que la tematización filosófica de Maliandi abreva constantemente no sólo en el canon filosófico (de Kant a Hartmann), sino también en otros ámbitos como el de la antropología, la sociología y también el de la literatura, ámbito que a mi modo de ver se destaca. Desde esta 
última se introducen intuiciones e ideas de un modo diferente, a menudo más fluido, dinámico y no exento de humor, a partir de lo cual la reflexión retoma el hilo de Ariadna de la conflictividad. Así, Maliandi introduce el tema de la conflictividad diacrónica con la siguiente cita del Tristram Shandy de Lawrence Sterne: "Tanto movimiento, continúa él (porque era muy corpulento) es demasiada intranquilidad, y mucho descanso, en la misma analogía es mucho de celestial. Ahora bien, yo (como soy muy delgado) pienso de modo distinto, y creo que el movimiento es mucho de vida y mucho de alegría, y que quedarse quieto o moverse pero lentamente es la muerte y el diablo". Esto se pone enseguida en relación con Platón y con la oposición que se pone en escena, la del movimiento frente a la permanencia.

Volviendo a la conflictividad, está claro que la ocupación filosófica principal de Maliandi no ha sido la metafísica sino la ética. Su "desvío" por cuestiones metafísicas no tiene otro objetivo que brindar una mejor explicación del trasfondo sobre el que opera la racionalidad. En esto último, el libro le dedica un espacio considerable al análisis de las diversas relaciones entre razón y pathos, los dos resortes de la conducta presentes en todo hombre, en donde se recorren posiciones tradicionales y se propone la actitud crítica como "mediadora" entre ambos resortes.

Maliandi entiende a la racionalidad como una "fuerza anti-conflictiva", independientemente de los "medios" de los que se valga para operar, ya sea encarnada en una búsqueda "sentimental" de armonía, ya sea en la forma de un discurso argumentativo en pos del consenso. Cuando la razón se vuelve discursiva, su orientación anti-conflictiva la vuelca hacia una búsqueda dialógica de propuestas de acción. Y la reflexión racional sobre estos intentos conduce, cuando es elaborada con un determinado grado de abstracción y rigor conceptual, al campo "científico" o ético-filosófico. Así, la ética como disciplina es una continuación elaborada, reflexiva y rigurosa de la actitud racional frente a los conflictos y sobre los modos justificados de tratarlos.

Este tomo aborda también en este tomo una serie de conflictos clásicos de la tradición filosófica, como el que opone convicción a responsabilidad y también aquel que enfrenta justicia a libertad. El trayecto argumentativo recoge posiciones históricamente sostenidas, recorre la complejidad de las estructuras conflictivas y presenta finalmente la "solución convergente", consistente en 
buscar el mayor equilibrio posible entre las instancias opuestas. Maliandi señala que se produce en cada uno de estos conflictos un "doble vínculo" - expresión tomada de la psicología- representado por exigencias opuestas, lo cual se duplica si se tiene en cuenta las dimensiones sincrónica y diacrónica de cada exigencia. Este "cuádruple vínculo", adelanta el autor, es un tema que será retomado en los tomos siguientes.

La parte final de este primer tomo de la Ética Convergente es un claro regreso a aquella fenomenología que ha servido de base a la propia ética convergente, la de Hartmann y su desvelamiento de estructura conflictivas propias de la moralidad como las de plenitud - pureza, inquietud - serenidad, y ayuda - respeto, aflorando diversos problemas de la filosofía de los valores, como el de su negación.

Si se quisiera hacer una periodización del pensamiento de Maliandi, creo que puede plantearse lo siguiente. Este primer tomo de la Ética Convergente se correlaciona claramente con una primera etapa desde el punto de vista cronológico, signada por la filosofía de los valores y su explicitación de estructuras en el ethos. El segundo tomo se corresponde con el posterior descubrimiento, por parte de nuestro autor, de la filosofía apeliana de la ética. Aquí Maliandi se enfrenta (o más bien se enfrentará) con una serie de problemas propios de la fundamentación ética. Finalmente, el tercer tomo presenta la propuesta de la Ética Convergente misma, enfocándose en la problemática de la aplicación ética.

Si bien esta periodización es a mi modo de ver bastante adecuada, descuida el hecho de que la Ética Convergente es ya desde su primera presentación en este primer tomo la teoría o el programa filosófico de base. Es desde su prisma que la reflexión regresa a la filosofía de los valores, defiende la fundamentación ética y aborda la cuestión de la aplicación. Así, el punto de llegada del trabajo de toda una vida está ya incorporado en la arquitectura de este primer tomo.

Creo que se trata de un proyecto destinado a permanecer y a fertilizar la reflexión futura. Las razones de ello son a mi juicio varias: se trata de una obra con muchas aristas y con abundancia de sugerencias originales, cada una de las cuales merece discusión y puede ser retomada y elaborada; establece un diálogo filosófico con la tradición filosófica y especialmente con el pensamiento 
contemporáneo; permite conceptualizar problemas complejos, especialmente en el ámbito de la moralidad; propone argumentos rigurosos y sensatos desde el punto de vista del "sentido común filosófico"; finalmente, entre otras razones de peso, no recrea meramente problemáticas de otros pensadores sino que desarrolla una filosofía nueva con una pluralidad de tesis y conceptos, elaborados a lo largo de décadas de discusión y reflexión.

Sin embargo, a mi modo de ver, lo anterior es poco en comparación con el principal mérito filosófico en una época en donde reinan posiciones "irracionalistas" o unilaterales: tiene sustancialmente razón. Esto se ve tanto en las tesis explícitas defendidas, como en el propio tratamiento de los temas aporéticos o no-, que tiene en Maliandi un carácter siempre sensato y multilateral. De este modo, si bien el concepto de "razón" no aparece mencionado en estos tomos, es un "Volver a la razón" lo que esta filosofía propugna, y en consonancia con ello dejo la palabra a Maliandi (en una cita que corresponde justamente al libro que lleva ese título):

"La vuelta a la razón debería entenderse [...] como la forma de rescatar del olvido (un olvido obstinadamente cultivado y propagado) el sencillo hecho de que la razón nos constituye, y de que no podemos arrojar por la borda lo auténticamente racional, como no podríamos arrojar realmente por la borda de un barco - permítaseme aquí un recurso contrametafórico- nuestros brazos, porque tenemos que valernos de ellos precisamente para arrojar algo por la borda. No nos es posible razonar contra la razón, como no nos es posible sacar a la calle a patadas a nuestros propios pies". I\$

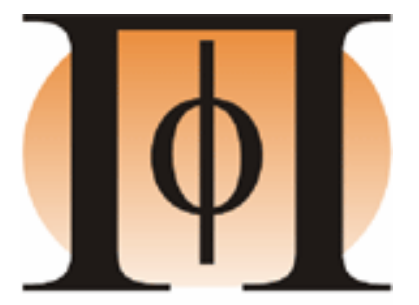

Andrés Crelier es doctor en Filosofía por UNLP, Argentina. Se desempeña como docente e investigador en UNMDP y como investigador asistente en CONICET. Es miembro de la Asociación Argentina de Investigaciones Éticas y de la Fundación para el Intercambio Cultural AlemánLatinoamericano (ICALA). 